\title{
PEMANFAATAN SISA PAKAN IKAN MAS OLEH IKAN NILA DALAM KJA GANDA YANG RAMAH LINGKUNGAN
}

\author{
Endang Pratiwi", Supriyono Eko Wardoyo*, \\ Ningrum Suhenda* ${ }^{* *}$ an Irin Iriana**
}

\begin{abstract}
ABSTRAK
Tujuan penelitian adalah untuk mendapatkan teknologi pemanfaatan sisa pakan ikan mas oleh ikan nila dengan efektif dan efisien dalam KJA ganda. Dengan adanya ikan nila pada keramba lapis luar, maka pengotoran lingkungan akibat sisa pakan ikan mas bisa dikurangi, sehingga kelangsungan budidaya dapat lestari.
\end{abstract}

Wadah percobaan yang digunakan adalah keramba jaring apung ganda dari bahan polietilen sebanyak 18 unit yang masing-masing terdiri atas dua lapis keramba, yaitu keramba lapis luar dan keramba lapis dalam. Ikan uji yang digunakan ikan mas dengan bobot rata-rata 66 g/ekor, padat penebaran $60 \mathrm{ekor} / \mathrm{m}^{3}$ dipelihara dalam keramba lapis dalam dan ikan nila bobot rata-rata 28 g/ekor dipelihara dalam keramba lapis luar. Ikan nila tidak diberi pakan tetapi hanya memakan sisa pakan ikan mas yang ada di keramba lapis dalam. Perlakuan yang diuji coba adalah perbedaan kepadatan nila (30,60 dan 90) ekor $/ \mathrm{m}^{3}$ dan perbedaan ransum harian ikan mas (sistem pompa dan sistem kenaikan bertahap). Rancangan percobaan adalah Rancangan Acak Lengkap dengan analisis faktorial, masing-masing dengan sembilan ulangan untuk ikan mas dan tiga kali ulangan untuk ikan nila.

Hasil penelitian menunjukkan bahwa untuk ikan mas, pemberian pakan dengan sistem pompa menghasilkan produksi yang lebih tinggi, meskipun konversi pakannya juga tinggi. Adapun untuk nila, produksi semakin tinggi pada padat tebar yang tinggi, tanpa adanya pengaruh dari sistem pemberian pakan. Sebaliknya sintasan ikan nila pada pemberian pakan sistem pompa ternyata lebih rendah dibandingkan sistem pemberian pakan dengan kenaikan bertahap, tanpa adanya pengaruh dari padat tebar. Konversi pakan ikan nila sangat dipengaruhi baik oleh sistem pemberian pakan maupun padat tebar. Padat tebar ikan nila 90 ekor/ $\mathrm{m}^{3}$ ternyata paling efisien digunakan dalam budidaya KJA ganda.

ABSTRACT: Utilization of common carp's uneaten feed by nile tilapia in environmentaly-sound floating double-net cage culture. By : Endang Pratiwi, Supriyono Eko Wardoyo, Ningrum Suhenda, and Irin Iriana.

The objective of the study was to achieve technology for utilization of common carp's uneaten feed by nile tilapia effectively and efficiently in the floating double-net cage culture. By the introduction of nile tilapia in the supplementary net-cage fixed outer the common carp cage, organic polllution due to the accumulation of uneaten feed and faeces of common carp could be minimized or avoided, thus a sustainable floating-net culture system could be achieved.

The experimental unit was 18 floating double-net cages made of polyethylene material. The tested fish were common carp with average weight of $66 \mathrm{~g}$, they were stocked in the inner net cage at $60 \mathrm{fish} / \mathrm{m}^{3}$ and nile tilapia with average weight of $28 \mathrm{~g}$ were stocked in the outer net cage. The nile tilapia ate only common carp's uneaten feed, which fell down through the inner net cage. Treatments applied were different nile tilapia stocking densities (30, 60 and $90 \mathrm{fish} / \mathrm{m}^{3}$ ) and different common carp daily feeding rates (pumping system and gradual increase system). The experimental design was Complete Randomized Design in factorial arrangement. Each treatment had nine replicates for common carps and three replicates for nile tilapia.

The results showed that for common carp, pumping system feeding gave higher total production of fish, eventhough the FCR was also high. As for nile tilapia, the fish production was higher at higher stocking density without any effect of feeding system. On the other hand, the survival rate

\footnotetext{
*) Peneliti pada Pusat Penelitian dan Pengembangan Perikanan

**) Peneliti pada Balai Penelitian Perikanan Air Tawar
} 
of nile tilapia fed by pumping system were lower than the other system, no matter the stocking density were. Meanwhile, the FCR seemed to be affected by both, feeding system and the stocking density. Stocking density of $90 \mathrm{fish} / \mathrm{m}^{3}$ was the most efficient to be applied in double net cage culture.

\section{KEYWORDS: floating double net cage culture, feeding system, nile tilapia, common carp.}

\section{PENDAHULUAN}

Usaha budidaya ikan mas (Cyprinus carpio L.) dalam Keramba Jaring Apung (KJA) di Waduk Saguling, Jatiluhur dan Cirata telah berkembang dengan pesat. Akibat pesatnya perkembangan budidaya ikan mas dalam KJA, produksi meningkat dengan cepat, yang membuat nilai jual makin rendah, karena peningkatan harga bahan konstruksi, bibit ikan dan pakan lebih cepat bila dibandingkan dengan peningkatan harga produksi budidaya, sehingga mengakibatkan petani menderita rugi (Sudradjat, 1992). Di samping itu petani ikan mas di waduk-waduk tersebut telah biasa memberi pakan ikan dengan sistem pompa yaitu pakan yang akan diberikan selama satu musim tanam sudah ditetapkan yaitu 10 kali dari bobot total benih yang akan ditanam. Sebagai contoh apabila benih ikan mas bobot total $300 \mathrm{~kg}$ (bobot awal 50 g/ekor, padat tebar $60 \mathrm{ekor} / \mathrm{m}^{3}$ ) ditanam pada keramba ukuran $7 \times 7 \times 2 \mathrm{~m}^{3}$, pakan yang diperlukan selama pemeliharaan sebesar 3000 kg. Pakan ini diberikan 3-5 kali sehari sampai ikan tidak mau makan lagi/satiasi (Pras, 1993). Pada pemberian pakan sistem pompa, diperkirakan banyak pakan yang terbuang. Pakan yang terbuang beserta kotoran ikan terakumulasi di dasar perairan, membusuk dan menurunkan kualitas air sehingga mengakibatkan pengotoran lingkungan. Jika terjadi peristiwa umbalan atau pengadukan sampai dasar, keadaan tersebut mencemari dan bisa mematikan ikan secara massal (Krismono et al., 1992)

Untuk mengatasi hal tersebut di atas, perlu dicari alternatif lain agar pendapatan petani meningkat dan pengotoran lingkungan berkurang, juga kegiatan budidaya bisa lestari. Salah satu cara adalah diversifikasi komoditas ikan yaitu dengan penambahan ikan nila (Oreochromis niloticus ) yang dapat memanfaatkan sisa pakan ikan mas yang terbuang dalam KJA sistem ganda.

Dalam KJA sistem ganda, ikan mas dipelihara dalam keramba lapis dalam dan ikan nila dalam keramba lapis luar. Ikan mas diberi pakan, sedangkan ikan nila tidak diberi pakan, tetapi hanya memanfaatkan pakan ikan mas yang tidak termakan dari keramba lapis dalam. Dengan demikian di samping pencemaran lingkungan karena sisa pakan berkurang, juga akan mendapatkan tambahan hasil ikan tanpa tambahan biaya pakan. Penelitian dilakukan untuk mendapatkan teknologi pemanfaatan sisa pakan ikan mas dengan efektif dan efisien dalam KJA ganda.

\section{BAHAN DAN METODE}

Percobaan dilakukan di Waduk Jatiluhur selama tiga bulan, yaitu pada bulan Agustus s/d November 1995. Lokasi penelitian berdampingan dengan lokasi KJA petani. Wadah percobaan yang digunakan adalah KJA ganda yang terdiri atas keramba lapis dalam dan keramba lapis luar dari bahan polietilen masing-masing sebanyak 18 buah. Keramba lapis dalam berukuran $1 \times 1 \times 1,3$ $\mathrm{m}^{3}$ (bagian yang tenggelam $1 \mathrm{~m}^{3}$ ) dan keramba lapis luar berukuran $1,3 \dot{\mathrm{x}} 1,3 \times 1,8 \mathrm{~m}^{3}$ (bagian yang tenggelam $1,3 \times 1,3 \times 1,5 \mathrm{~m}^{3}$ ) (Gambar 1). KJA ganda tersebut ditambatkan pada rakit-rakit bambu yang diberi pelampung berupa drum bekas.

Ikan uji yang digunakan adalah ikan mas dengan bobot awal rata-rata 66 g/ekor, padat penebaran 60 ekor $/ \mathrm{m}^{3}$ (sesuai dengan kepadatan yang dipraktekkan petani) dipelihara di keramba lapis dalam dan ikan nila dengan bobot awal ratarata 28 g/ekor dipelihara di keramba lapis luar. Ikan nila tidak diberi pakan, hanya memanfaatkan sisa pakan ikan mas yang lolos dari keramba lapis dalam. Ikan mas diberi pakan komersial yang ada di pasaran dengan kadar protein $25,02 \%$, yakni berupa pelet tenggelam.

Perlakuan dengan dua faktor peubah yaitu: perbedaan sistem pemberian pakan ikan mas (sistem kenaikan bertahap dan sistem pompa) dan perbedaan padat penebaran ikan nila $(30,60$ dan $90 \mathrm{ekor} / \mathrm{m}^{3}$ ). Untuk pemberian pakan dengan sistem bertahap, pakan sebanyak 3\% dari bobot 


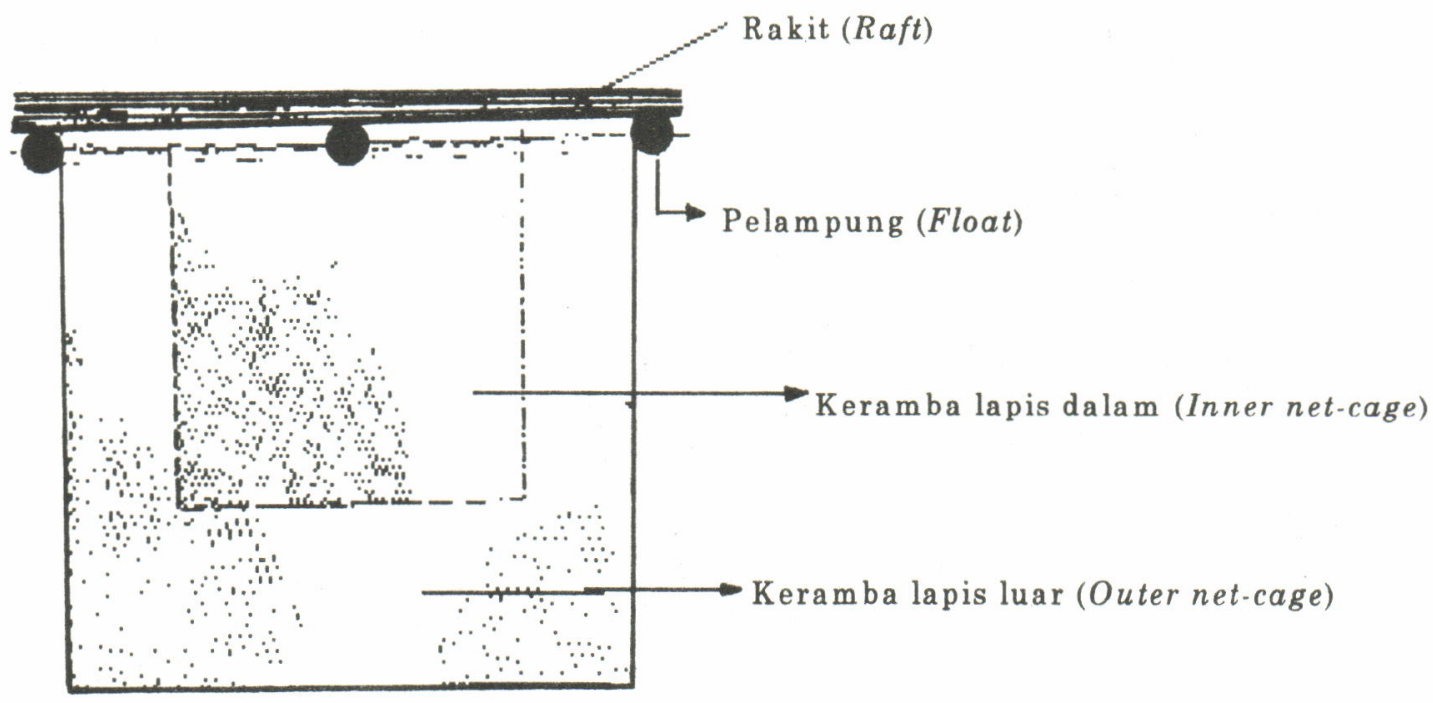

Gambar 1. Keramba jaring apung ganda

Figure 1. Floating double-net cage

biomassa ikan diberikan tiga kali sehari yaitu pukul 08, 12, dan 16. Jumlah pakan ditingkatkan secara bertahap disesuaikan dengan bobot ikan setiap dua minggu setelah penimbangan sampel ikan. Sedangkan untuk sistem pompa (sistem di petani), pakan yang diberikan sebanyak 10 kali bobot total benih, untuk masa pemeliharaan tiga bulan diberikan lima kali sehari yakni pada pukul $08.00,10.00,12.00,14.00$, dan 16.00 sampai ikan tidak mau makan lagi (satiasi).Untuk mengetahui pengaruh kepadatan ikan nila dan pengaruh pemberian pakan terhadap pertambahan bobot individu, sintasan, konversi pakan, dan produksi ikan nila digunakan rancangan acak lengkap dengan analisis faktorial dengan tiga kali ulangan, dan untuk mengetahui pengaruh perbedaan pemberian pakan terhadap pertambahan bobot, sintasan, konversi pakan dan produksi ikan mas digunakan rancangan yang sama dengan sembilan ulangan, FCR ikan nila dihitung dengan asumsi sisa pakan sebanyak $31 \%$ untuk sistem kenaikan bertahap, dan 38\% untuk sistem pompa. Angka asumsi ini diperoleh dari hasil percobaan pendahuluan.

Pengamatan pertumbuhan dan penyesuaian pemberian ransum dilakukan setiap dua minggu dengan cara menimbang ikan sampel sebanyak 10 ekor setiap keramba. Sebagai data penunjang dilakukan pengamatan kualitas air. Parameter kualitas air yang diamati meliputi: suhu, $\mathrm{pH}, \mathrm{O}_{2}$, alkalinitas, nitrit, $\mathrm{CO}_{2}$, fosfat dan amonia. Pengamatan kualitas air dilakukan sebulan sekali, yakni sebelum melakukan sampling pertumbuhan ikan, yaitu sekitar pukul 09.00 WIB. Pengambilan sampel air dilakukan di tiga titik peng. amatan, yaitu waktu air masuk ke arah KJA, pada lingkungan KJA dan pada air yang keluar KJA (disesuaikan dengan arah aliran air waduk).

\section{HASIL DAN PEMBAHASAN}

Hasil analisis data dan pembahasan mengenai pertambahan bobot mutlak individu, produksi, konversi pakan dan sintasan untuk ikan mas dan nila serta sifat fisika dan kimia air selama tiga bulan percobaan diuraikan sebagai berikut:

\section{Pertambahan Bobot Mutlak Individu}

Pada ikan mas, pemberian pakan sistem pompa menghasilkan pertambahan bobot mutlak individu yang tidak berbeda dibandingkan dengan sistem kenaikan bertahap $(P>0,05)$. Ransum pakan harian sistem pompa memberikan pertambahan bobot mutlak individu rata-rata $80,89 \pm 19,19$ g sedangkan sistem kenaikan bertahap memberikan pertambahan bobot mutlak 
individu rata-rata $69,78 \pm 15,06 \mathrm{~g}$ ('Tabel 1). Perbedaan yang tidak nyata ini kemungkinan disebabkan karena tingginya variasi bobot ikan secara individu.

Adapun pada ikan nila, perbedaan sistem pemberian pakan ikan mas maupun perbedaan padat penebaran nila tidak memberikan perbeda- an nyata $(\mathrm{P}>0,05)$ terhadap pertambahan bobot mutlak rata-rata individu (Tabel 1). Demikian juga interaksi antara perbedaan sistem pem. berian pakan ikan dan perbedaan kepadatan ikan nila tidak berpengaruh terhadap pertambahan bobot mutlak rata-rata individu ikan nila pada akhir penelitian (panen).

Tabel 1. Rata-rata pertambahan bobot mutlak individu (g), produksi bersih (kg), sintasan (\%)dan konversi pakan ikan mas dan nila selama 3 bulan pemeliharaan dalam KJA sistem ganda.

Table 1. Average absolute growth (g), net production ( $\mathrm{kg})$, survival rate (\%) and feed coversion ratio of common carp and nile tilapia during 3 months rearing period in double-net cage culture.

\begin{tabular}{|c|c|c|c|}
\hline \multirow[b]{2}{*}{ No. } & \multirow[b]{2}{*}{ Parameter } & \multicolumn{2}{|c|}{$\begin{array}{c}\text { Sistem pemberian pakan } \\
\text { Feeding system } \\
\end{array}$} \\
\hline & & $\begin{array}{c}\text { Kenaikan bertahap } \\
\text { Gradual increase }\end{array}$ & $\begin{array}{c}\text { Sistem pompa } \\
\text { Pumping system }\end{array}$ \\
\hline
\end{tabular}

Ikan mas (keramba lapis dalam)

Common carp (inner net cage)

1. Padat penebaran $\left(\mathrm{ekor} / \mathrm{m}^{3}\right)$

60

$67.63 \pm 15.06^{\mathrm{a}}$

2. Pertambahan bobot mutlak rata-rata individu $(\mathrm{g})$

Average absolute individual growth $(g)$

3. Produksi total $(\mathrm{kg})$ Total production ( $\mathrm{kg}$ )

4. Sintasan (\%) Survival rate $(\%)$

5. Konversi pakan Feed Conversion Ratio (FCR)

\section{Sistem pemberian pakan}

Feeding system

Ikan nila (keramba lapis luar)

Nile tilapia (outer net cage)

1. Padat penebaran (ekor $\left./ \mathrm{m}^{3}\right)$ Stocking density ( $f$ ish $\left./ \mathrm{m}^{3}\right)$
$7.70 \pm 332^{\mathrm{n}}$
$8.38 \pm 625^{b}$
$93.0 \pm 5.11^{\mathrm{n}}$
$90.0 \pm 6.38^{\mathrm{a}}$
$2.66 \pm 0.22^{a}$
$5.80 \pm 1.06$

$2.66 \pm 0.22^{\mathrm{a}} \quad 5.80 \pm 1.06^{\mathrm{b}}$

2. Pertambahan bobot mutlak rata-rata individu (g)

Average absolute individual growth (g)

3. Produksi total $(\mathrm{kg})$

Total production $(\mathrm{kg})$

4. Sintasan (\%)

Survival Rate (\%)

60

90

30

60

90

$162.3^{\mathrm{a}}$

$173.0^{\mathrm{a}}$

$151.7^{\mathrm{a}}$

$190.7^{\mathrm{a}} \quad 168.3^{\mathrm{a}}$

$164.7^{\mathrm{a}}$

Konversi pakan

Feed Conversion Ratio (FCR)

$\begin{array}{cccccc}5.42^{\mathrm{a}} & 10.88^{\mathrm{b}} & 14.67^{\mathrm{c}} & 5.50^{\mathrm{a}} & 8.33^{\mathrm{ab}} & 15.67^{\mathrm{c}} \\ 94.5^{\mathrm{a}} & 91.1^{\mathrm{a}} & 91.9^{\mathrm{a}} & 83.3^{\mathrm{ab}} & 71.1^{\mathrm{b}} & 90.4^{\mathrm{a}} \\ 0.90^{\text {ad }} & 0.47^{\mathrm{ab}} & 0.37^{\mathrm{b}} & 3.20^{\mathrm{c}} & 2.07^{\mathrm{c}} & 1.17^{\mathrm{d}}\end{array}$

Nilai dalam kolom yang diikuti huruf yang sama secara statistik berbeda tidak nyata (The value in the column followed by similar letters are statistically not different $(P>0.05)$ 
Hal ini menunjukkan bahwa sistem pemberian pakan dengan sistem kenaikan bertahap maupun sistem pompa pada ikan mas tetap menghasilkan sisa yang cukup banyak untuk dapat dimanfaatkan oleh ikan nila, bahkan dengan kepadatan yang tinggi. Untuk ikan mas, pertambahan bobot dari kedua sistem pemberian pakan sangat lambat hingga bulan kedua, dan baru terlihat perbedaannya setelah mencapai bulan ke tiga. Sedangkan untuk ikan nila, kenaikan bobot ikan terjadi secara bertahap untuk kedua macam sistem pemberian pakan (Gambar 2).

\section{Produksi Total}

Perbedaan sistem pemberian pakan ikan mas memberikan perbedaan nyata terhadap produksi ikan mas $(\mathrm{P}<0,05)$. Hal ini berarti bahwa walaupun sistem pemberian pakan tidak memberikan perbedaan nyata terhadap pertambahan bobot mutlak rata-rata individu akan tetapi berpengaruh nyata terhadap produksi ikan mas yaitu rata-rata $7,70 \pm 332 \mathrm{~kg}$ untuk sistem ke- naikan bertahap dan $8,38 \pm 625 \mathrm{~kg}$ untuk sistem pompa (Tabel 1).

Pada ikan nila, perbedaan sistem pemberian pakan tidak memberikan perbedaan yang nyata terhadap produksi nila $(P>0,05)$, akan tetapi perbedaan kepadatan ikan nila memberikan perbedaan yang nyata terhadap produksinya $(\mathrm{P}<0,05)$. Dari angka mutlaknya terlihat bahwa kepadatan nila 90 ekor $/ \mathrm{m}^{3}$ dengan pemberian pakan sistem pompa menunjukkan produksi paling tinggi yaitu $15,67 \mathrm{~kg}$ dan produksi terendah pada kepadatan $30 \mathrm{ekor} / \mathrm{m}^{3}$ dengan pemberian pakan sistem kenaikan bertahap yaitu $5,42 \mathrm{~kg}$ (Tabel 1). Petani pada umumnya menggunakan kepadatan nila di KJA ganda $60 \mathrm{ekor} / \mathrm{m}^{3}$ (Pras, 1993). Interaksi antara perbedaan ransum harian mas dan perbedaan kepadatan ikan nila tidak memberikan perbedaan nyata terhadap produksi ikan nila $(P>0,05)$, sehingga untuk memperoleh produksi yang lebih baik dalam keramba jaring apung ganda, kepadatan nila yang efektif dengan sistem pemberian pakan yang manapun adalah $90 \mathrm{ekor} / \mathrm{m}^{3}$.

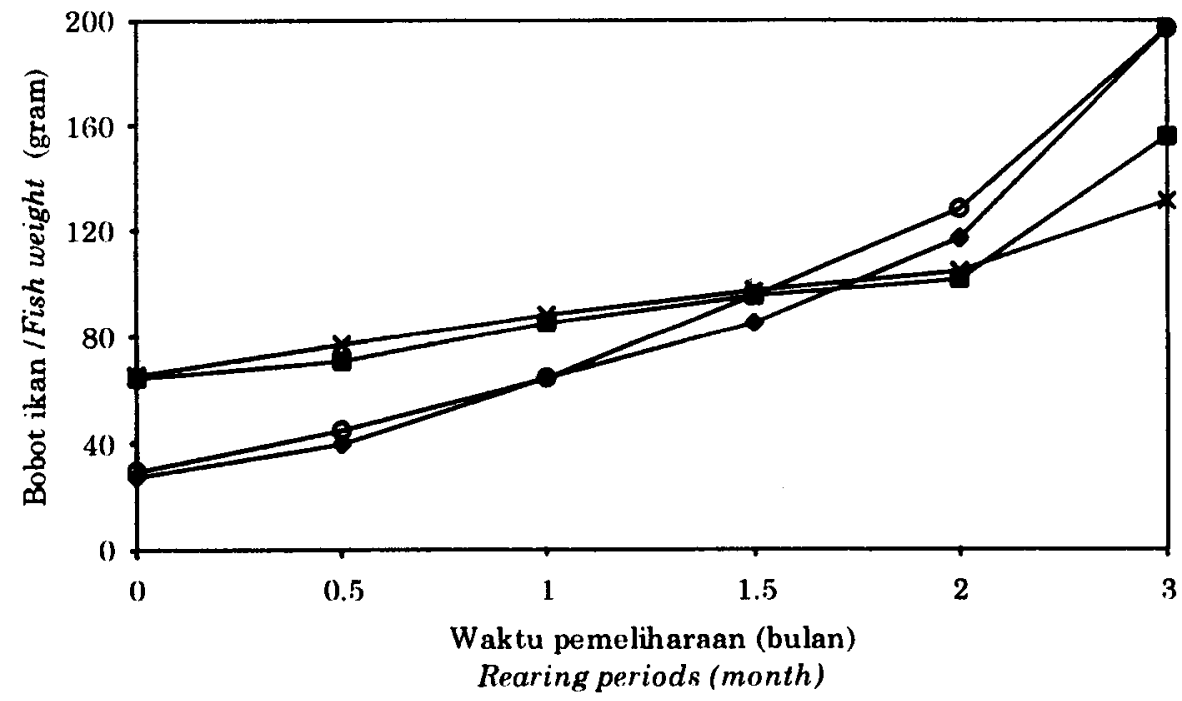

$\rightarrow-$ Mas $3 \% \rightarrow-$ Mas Pompa - Nila $3 \% \multimap-$ Nila Pompa

Gambar 2. Pertambahan bobot ikan mas dan nila (g) selama tiga bulan pemeliharaan pada kepadatan $60 \mathrm{ekor} / \mathrm{m}^{3}$ dengan ransum pakan yang berbeda ( $3 \%$ bobot biomassa ikan dan sistem pompa).

Figure 2. Common carp and nile tilapia weight growth (g) during three months rearing period at 60 fish $/ \mathrm{m}^{3}$ with different feeding rate ( $3 \%$ biomass weight and pumping system). 


\section{Sintasan}

Pada ikan mas, perbedaan pemberian pakan tidak memberikan perbedaan nyata terhadap sintasan ikan mas $(\mathrm{P}>0,05)$, masing-masing dengan nilai rata-rata $93 \pm 5,11 \%$ untuk sistem kenaikan bertahap dan $90 \pm 6,38 \%$ untuk sistem pompa (Tabel 1). Akan tetapi untuk ikan nila, perbedaan pemberian pakan memberikan perbedaan nyata $(\mathrm{P}<0,05)$ terhadap sintasan ikan nila (Tabel 1), walaupun padat penebaran ikan maupun interaksi antara kedua perlakuan tidak berpengaruh.

\section{Konversi Pakan (FCR)}

Perhitungan konversi pakan dalam penelitian ini adalah berdasarkan jumlah total pakan yang betul-betul dimanfaatkan oleh ikan mas, yang jumlahnya dihitung berdasarkan sisa pakan ikan mas dari penelitian pendahuluan. Dari penelitian pendahuluan ini diperoleh hasil bahwa jumlah pakan yang dimanfaatkan oleh ikan mas sebesar adalah $69 \%$ untuk sistem kenaikan bertahap dan $62 \%$ untuk sistem pompa. Dengan demikian sisa pakan yang bisa dimanfaatkan oleh ikan nila yang ada di keramba lapis luar adalah sebesar $31 \%$ untuk sistem kenaikan bertahap dan $38 \%$ untuk sistem pompa.

Pada ikan mas, pemberian pakan dengan sistem kenaikan bertahap ternyata lebih efisien pemanfaatannya dibandingkan sistem pompa $(\mathrm{P}<0,05)$ yaitu dengan konversi pakan $(\mathrm{FCR}) 2,66$ $\pm 0,22$ untuk sistem kenaikan bertahap dan 5,80 $\pm 1,06$ untuk sistem pompa (Tabel 1). Terlihat bahwa pemberian pakan sistem pompa (sistem yang dipraktekkan oleh petani) tidak efisien, hanya pemborosan pakan. Seperti telah diketahui bahwa dalam budidaya intensif pengeluaran biaya pakan dapat mencapai $60 \%-65 \%$ dari biaya produksi (Suhenda, 1995). Jadi pemberian pakan sistem kenaikan bertahap lebih efisien, karena dapat menekan biaya produksi.

Untuk ikan nila, perbedaan pemberian pakan ikan mas dan perbedaan padat penebaran ikan nila memberikan perbedaan nyata $(\mathrm{P}<0,05)$ terhadap konversi pakan ikan nila. Interaksi antara perbedaan pemberian pakan ikan mas dan perbedaan padat penebaran ikan nila juga memberikan perbedaan nyata $(P<0,05)$ terhadap konversi pakan ikan nila. Pada padat penebaran ikan nila lebih tinggi, ternyata konversi pakan cenderung lebih kecil, baik untuk sistem kenaikan bertahap maupun sistem pompa. Pada ransum pakan sistem pompa, ikan nila dengan kepadatan 30,60 dan 90 ekor $/ \mathrm{m}^{3}$ mempunyai nilai konversi pakan masing-masing 3,20;2,07 dan 1,17 (Tabel 1), hal ini ada kecenderungan bahwa sisa pakan ikan mas tidak dimanfaatkan seluruhnya oleh ikan nila, sehingga pemberian pakan ikan mas dengan sistem pompa kurang efisien dan mencemari lingkungan. Adapun ikan nila dengan pemberian pakan sistem bertingkat dan kepadatan 30,60 dan $90 \mathrm{ekor} / \mathrm{m}^{3}$ nilai konversi pakan masingmasing adalah 0,$90 ; 0,47$ dan 0,37 (Tabel 1 ), yang menunjukkan bahwa ikan nila selain memanfaatkan sisa pakan ikan mas juga memakan plankton dan lumut yang sudah ada dalam media air, karena memang ikan nila mempunyai sifat pemakan plankton (Jangkaru et al., 1991). Selain itu ikan nila juga dapat mengurangi pencemaran lingkungan, karena ikan nila dapat memanfaatkan sisa pakan ikan mas yang tidak termakan dari keramba lapis dalam, dan tidak tertimbun di dasar perairan.

\section{Sifat Fisika dan Kimia Air}

Hasil pengukuran parameter sifat fisika dan kimia air selama tiga bulan pemeliharaan tertera pada Tabel 2. Sifat fisika dan kimia air dapat mempengaruhi kehidupan dan pertumbuhan ikan yang dipelihara pada perairan tersebut. Hasil pengukuran selama penelitian menunjukkan bahwa suhu air pada pukul 09.00 pagi berkisar antara $24-32^{\circ} \mathrm{C}$. Suhu mempengaruhi nafsu makan ikan, laju pencernaan dan laju metabolisme yang selanjutnya mempengaruhi laju pertumbuhan (Hickling, 1971). Pada waktu penelitian dilaksanakan di Waduk Jatiluhur, sudah menjelang musim penghujan yang kadang-kadang diikuti angin kencang dan gelombang, hal ini kemungkinan yang menyebabkan pertumbuhan ikan lambat, karena metabolismenya terganggu.

Tabel 2 menunjukkan bahwa pH, alkalinitas, $\mathrm{CO}_{2}, \mathrm{O}_{2}, \mathrm{NH}_{3}$ dan $\mathrm{PO}_{4}$ masih pada kondisi yang baik untuk kehidupan ikan, namun $\mathrm{NO}_{2}$ (nitrit) relatif tinggi $(0,281-0,955 \mathrm{mg} / \mathrm{L})$, bahkan telah melampaui ambang batas $(0,06 \mathrm{mg} / \mathrm{L})$. Hal ini menunjukkan bahwa lingkungan perairan budidaya sudah tercemar oleh limbah metabolik, karena $\mathrm{NO}_{2}$ adalah salah satu limbah metabolik yang dihasilkan oleh kegiatan biologi yang berhubungan dengan penguraian bahan organik dari 
Tabel 2. Kisaran kualitas air di lingkungan KJA .

Table 2. Water quality range in the floating net cage area.

\begin{tabular}{ccccc}
\hline $\begin{array}{c}\text { Parameter } \\
\text { Parameters }\end{array}$ & $\begin{array}{c}\text { Kisaran } \\
\text { Range }\end{array}$ & $\begin{array}{c}\text { Rataan } \\
\text { Mean }\end{array}$ & $\begin{array}{c}\text { Nilai standar } \\
\text { Standard value }\end{array}$ & $\begin{array}{c}\text { Sumber } \\
\text { Source }\end{array}$ \\
\hline Suhu $($ Temp. $)\left({ }^{\circ} \mathrm{C}\right)$ & $24-32$ & 28.2 & $28-32$ & Boyd (1984) \\
$\mathrm{pH}$ & $6.3-8$ & 7.65 & $6-9$ & KLH (1988) \\
Alk. $(\mathrm{mg} / \mathrm{L})$ & $18.9-48$ & 31.95 & $30-280$ & Stickney (1979) \\
$\mathrm{CO}_{2}(\mathrm{mg} / \mathrm{L})$ & $1.97-5.97$ & 2.80 & $<10$ & Boyd (1984) \\
$\mathrm{O}_{2}(\mathrm{mg} / \mathrm{L})$ & $3.9-8.9$ & 6.69 & $>5$ & Boyd (1984) \\
$\mathrm{NO}_{2}(\mathrm{mg} / \mathrm{L})$ & $0.281-0.955$ & 0.72 & 0.06 & KLH (1988) \\
$\mathrm{NH}_{3}(\mathrm{mg} / \mathrm{L})$ & $0-0.08$ & 0.41 & $<1$ & KLH (1988) \\
$\mathrm{PO}_{4}(\mathrm{mg} / \mathrm{L})$ & $0.149-0.6$ & 0.67 & $0.06-10$ & Goldman and \\
& & & & Horne (1983) \\
\hline
\end{tabular}

komponen-komponen protein, yang sebagian besar berasal dari pakan yang lolos tidak dimakan oleh ikan maupun dari kotoran ikan (Schmittou, 1991). Dan ternyata satu setengah bulan setelah penelitian selesai, tepatnya pada tanggal 5 Januari 1996 di Waduk Jatiluhur terjadi peristiwa umbalan yang diikuti kematian massal (sebanyak 1.600 ton ikan mati) dan kadar $\mathrm{NO}_{2}$ meningkat antara 0,990-1,484 $\mathrm{mg} / \mathrm{L}$ (Krismono et al., 1996).

\section{KESIMPULAN DAN SARAN}

Dari hasil penelitian dapat diambil kesimpulan sebagai berikut :

1. Pada budidaya KJA sistem ganda ikan nila pada keramba lapis luar dapat memanfaatkan sisa pakan ikan mas yang lolos dari keramba lapis dalam.

2. Dilihat dari konversi pakan ikan mas serta sintasan dan konversi pakan ikan nila, pem. berian pakan ikan mas dengan sistem kenaikan bertahap ternyata lebih efisien dari pemberian pakan sistem pompa. Demikian pula padat penebaran ikan nila $90 \mathrm{ekor} / \mathrm{m}^{3}$ lebih efisien dalam pemanfaatan pakan dari pada padat penebaran lainnya (30 dan 60 ekor $\left./ \mathrm{m}^{3}\right)$.
3. Untuk lebih meningkatkan pendapatan petani disarankan agar pemberian pakan ikan mas oleh petani cukup 3\% bobot biomassa dengan kenaikan bertahap sesuai bobot ikan dan kepadatan ikan nila ditingkatkan dari 60 menjadi $90 \mathrm{ekor} / \mathrm{m}^{3}$.

\section{DAFTAR PUSTAKA}

Boyd, C.E. 1979. Water Quality Warm Water Fish Pond. Auburn University. Aquacultural Experiment Station. Alabama, $350 \mathrm{pp}$.

Goldman, C.R. and A.J. Horne. 1983. Limnology Int. Student Ed. Mc Graw Hill Inc. 464 pp.

Hickling, C.F. 1971. Fish culture. Faber and Faber. London. 317 pp.

Jangkaru, Z., A. Widayati, A. Hardjamulia, F. Sukadi, N. Suhenda, P. Yuliati, Sutrisno, P. Taufik dan Y. P. Haryani. 1991. Petunjuk Teknis Budidaya Ikan Nila.PHP/KAN/PT.17/1991. Pusat Penelitian dan Pengembangan Perikanan, Jakarta. $62 \mathrm{pp}$.

KLH, SK Menteri KLH No. 2 th. 1988. Tentang Baku Mutu Lingkungan Hidup, Kantor Meneg Lingkungan Hidup.

Krismono, A., K. Purnomo dan D. W. H. Tjahjo. 1992. Proses pembalikan/umbalan dan dampaknya terhadap kegiatan perikanan, dalam Prosiding Temu Karya Ilmiah Pengkajian Alih Teknologi Budidaya Ikan Dalam Karamba Mini. Bogor 4-6 Maret 1991: 42-47. 
Krismono, A. Sarnita dan A. Rukyani. 1996. 1600 ton ikan mati di Waduk Jatiluhur. Warta Penelitian Perikanan Indonesia Vol. 1(1) : 5-7.

Pras, H. 1993. Polikultur nila dan mas. TECHNER No. 7. Th II : 34-35.

Schmittou, H.R. 1991. Budidaya keramba suatu metode produksi ikan di Indonesia, FRDP, Puslitbang Perikanan, Jakarta. $126 \mathrm{pp}$.

Stickney, R.R. 1979. Principles of warm-water aquaculture.John Willey and Sons, New York. 199 pp.
Sudradjat, L.I. 1992. Permasalahan budidaya ikan dalam keramba jaring apung di Saguling dan Cirata, dalam Prosiding Temu Karya Ilmiah Pengkajian Alih Teknologi Budidaya Ikan dalam Keramba Mini, Bogor 4-6 Maret 1991: 128 - 133.

Suhenda, N. 1995. Pakan optimal mendukung budidaya ikan dalam KJA yang ramah lingkungan. Makalah disampaikan pada Ekpose Teknologi Budidaya Ikan dalam KJA yang Ramah Lingkungan pada Hari Krida Pertanian XXIII 19 Juli 1995 di Jatiluhur (tidak dipublikasikan) 14 pp. 